\title{
Generalization of Habituation and Intrinsic Sensitization in the Leech
}

\author{
Brian D. Burrell ${ }^{1}$ and Christie L. Sahley \\ Department of Biological Sciences \\ Purdue University \\ West Lafayette, Indiana 47907 USA
}

\begin{abstract}
Using the shortening reflex of the medicinal leech Hirudo medicinalis we examined stimulus generalization of habituation learning. Preparations received mechanosensory stimulus at two positions on the leech body wall, one site used to carry out habituation training and a second novel site to test for generalization of habituation. After training, the specific mechanosensory neurons activated by each stimulus were assessed using intracellular recordings. As expected, the closer the two sites were to each other, the greater the degree of generalization of habituation at the novel site and the more sensory cells were shared. However, a form of behavioral facilitation was observed at the trained site that resembled behavioral sensitization, but differed from the standard sensitization process in several respects. (1) Facilitation was induced by stimulation of the novel site before habituation training at the trained site, although the stimulus intensity at the novel site was equivalent to the training stimuli and was not the strong, noxious stimuli that normally induce sensitization. (2) The magnitude of the facilitating effect was proportional to the proximity of the novel and trained stimulation sites. (3) Although behavior at the trained site was facilitated, behavior at the novel site was habituated, indicating that the induced behavioral facilitation did not generalize throughout the animal, as normally occurs during sensitization, but was limited to a single stimulus-response pathway.
\end{abstract}

${ }^{1}$ Corresponding author. Present address: Department of Physiology and Biophysics, University of Miami School of Medicine, Miami, Florida 33136 USA.

\section{Introduction}

A critical feature of learning in any animal is the ability to discriminate between learned and novel stimuli. Failure to discriminate between a trained $\left(\mathrm{S}_{\mathrm{T}}\right)$ versus a novel $\left(\mathrm{S}_{\mathrm{N}}\right)$ stimulus could result in an inappropriate response. The degree to which this generalization occurs depends on how similar $\mathrm{S}_{\mathrm{T}}$ and $\mathrm{S}_{\mathrm{N}}$ stimuli are to each other (Mackintosh 1974). It is suggested that this is determined at a physiological level by the number neural elements shared by $\mathrm{S}_{\mathrm{T}}$ and $\mathrm{S}_{\mathrm{N}}$, both at afferent and integration levels. In addition, generalization can be affected by the type of learning that the animal undergoes. For example, it is believed that associative learning and habituation involve modification of a behavioral response to a specific stimulus, therefore, the level of generalization of the learned behavior to other novel stimuli is low (Mackintosh 1974; Stopfer et al. 1996). In contrast, sensitization is thought to alter behavior throughout the animal, in effect, generalizing to many if not all stimulusresponse pathways (Carew et al. 1971; Boulis and Sahley 1988; Davis 1989; Lockery and Kristan 1991).

The whole-body shortening reflex of the medicinal leech Hirudo medicinalis has been a useful system for studying associative and nonassociative forms of learning (Sahley 1995). This defensive behavior may be elicited by either photic or mechanosensory stimulation that generates a coordinated contraction of all the leech body segments (Lockery et al. 1985; Boulis and Sahley 1988). Mechanosensory stimuli in the leech are detected by at least three classes of sensory neurons. In order of most to least sensitive, they are the touch (T), pressure $(\mathrm{P})$, and nociceptive $(\mathrm{N})$ cells. Every segmental ganglion contains three $\mathrm{T}$, two $\mathrm{P}$, and two $\mathrm{N}$ cells innervating each side of the body. The receptive fields of the $\mathrm{T}$ and $\mathrm{P}$ cells innervate a discrete region of skin along the medial (ventral/dorsal) axis of the body segment (Nicholls and Baylor 1968;

LEARNING \& MEMORY 5:405-419 @ 1998 by Cold Spring Harbor Laboratory Press ISSN1072-0502/98 \$5.00

$$
\begin{array}{lllllllllllllll}
L & E & A & R & N & I & N & G & \boldsymbol{Q} \\
405 & M & E & M & O & R & Y
\end{array}
$$


Yau 1976) providing the leech with positional information about the stimulation site (Lockery and Kristan 1990a; Lewis and Kristan 1998).

Whole-body shortening requires stimulation of the body wall sufficient to activate two P cells with adjacent receptive fields and associated $T$ cells (Shaw and Kristan 1995). This stimulation results in contraction of the longitudinal muscles starting at the site of stimulation as a result of activity from the L-motor neuron and the dorsal and ventral excitatory (DE and VE, respectively) motor neurons in each body segment (Fig. 1) (Stuart 1970; Shaw and Kristan 1995). The reflex spreads throughout the body as a result of activity from an unknown intersegmental neural pathway and a chain of interconnected interneurons called the $\mathrm{S}$ cell. The $\mathrm{S}$ cell, although not critical to the whole-body shortening reflex (Sahley et al. 1994), does contribute to the behavior by virtue of its excitatory input to the L cell (Gardener-Medwin et al. 1973; Shaw and Kristan 1995).

Given the requirement for whole-body short-

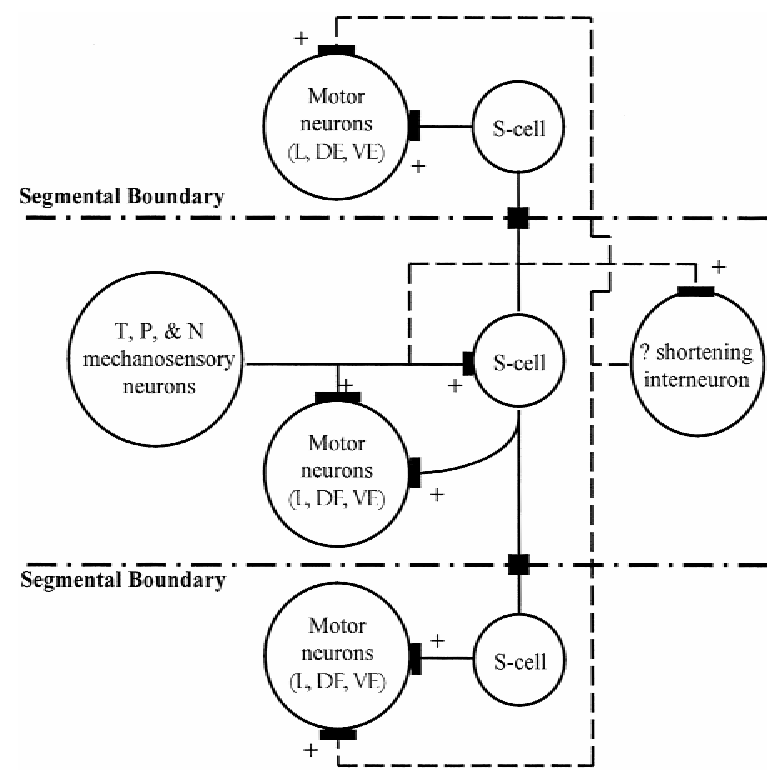

Figure 1: Simplified diagram of the neural circuit mediating the leech whole-body shortening reflex. Mechanosensory input to the skin is transduced by $\mathrm{T}, \mathrm{P}, \mathrm{N}$ cells that stimulate activity in the motor neurons, which induce contraction of the longitudinal muscles. The signal to shorten is carried to motor units throughout the body by the $S$ cell and a second, unidentified interneuron. The presence of this latter cell has been inferred by Shaw and Kristan (1995) and all inputs to and outputs from this cell (dashed lines) are hypothetical. Solid rectangles connecting adjacent $\mathrm{S}$ cells represent electrical synapses. ening to activate multiple mechanosensory cells across two receptive fields, we asked how similar must two mechanosensory stimuli be in terms of position on the body wall before habituation training at one site generalizes to whole-body shortening initiated at a second novel site. Using a combination of behavioral and electrophysiological techniques, we examined how habituation generalized between two stimulus-response pathways. In addition, these experiments revealed a form of behavioral facilitation, resembling sensitization, that did not generalize throughout the entire animal, but was specific to a single stimulus-response pathway.

\section{Materials and Methods}

\section{QUASI-INTACT PREPARATION}

Each leech was anesthetized by cooling at $4{ }^{\circ} \mathrm{C}$ and all dissections were carried out in normal leech saline (Muller et al. 1981) maintained at $4^{\circ} \mathrm{C}$. A longitudinal incision was made down the dorsal midline of the leech between segments 3 and 9 . The next two segments (10 and 11) were left intact and the ventral nerve cord (VNC) was dissected out from segments 12 to 13 (Fig. 2). The preparation was then pinned onto a Sylgard-lined dish ventral side up so that the body wall portion of the preparation (segments 3-9) formed a flat sheet and the dish was filled with leech saline. Pairs of 0.2$\mathrm{mm}$ Teflon-coated silver wire (Medwire) electrodes were implanted in the skin and bared at the point of contact with the skin to stimulate discrete areas of the leech body wall. One pair of electrodes was designated $\mathrm{S}_{\mathrm{T}}$ (trained site) and would be used for habituation training. A second pair of electrodes was designated $S_{\mathrm{N}}$ (novel site) and would be used to test for generalization of habituation. Both electrode pairs were implanted in the same body segment (segment 8), but in differing positions so that they activated different mechanosensory receptive fields within that segment. In addition, a window was cut in the ventral midline of the body wall to expose the segmental ganglia containing the sensory cells that would be activated by either stimulation site (segments 7-9). A third pair of electrodes $\left(\mathrm{S}_{\mathrm{DH}}\right)$ was implanted in segment 4 and was used to deliver dishabituating stimuli to the preparation.

The intact portion of the preparation was connected to an isometric tension transducer (Grass Instruments) to record the magnitude of the short-

$$
\begin{array}{lllllllllllllll} 
& E & A & R & N & I & N & G & \underset{406}{\mathbf{Q}} & M & E & M & O & R & Y
\end{array}
$$




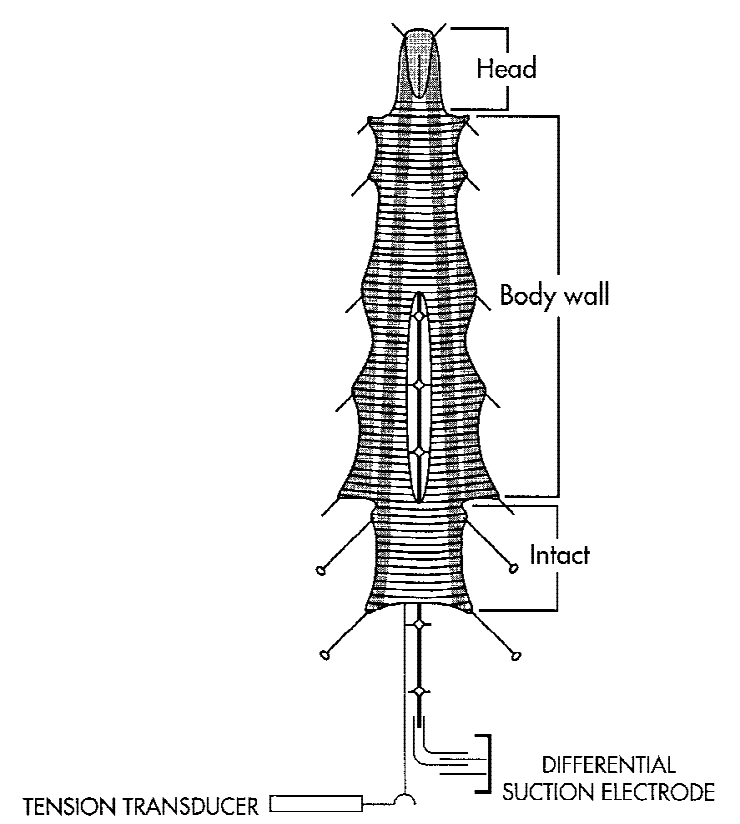

Figure 2: Diagram of the quasi-intact preparation used in habituation generalization experiments. Electroshock stimulus was delivered using silver wire electrodes (not shown) implanted in the body wall portion of the preparation and behavior was measured using a tension transducer attached to the intact portion of the preparation. A window was opened in the body wall to expose the ganglia from segments 7 to 9 . Neural activity in the VNC was recorded using a suction electrode.

ening response. A suction electrode on the VNC was used to record activity from the S cell, which generates the largest action potential in extracellular recordings of the VNC (Bagnoli et al. 1972). For some of the preparations examined, a branch of the dorsal posterior segmental nerve (DP:B1) that contains the axon for the L-motor neuron (Ort et al. 1974) was exposed and activity from that cell was recorded using a second suction electrode. Extracellular recordings were made using a Grass $\mathrm{P} / 5$ A.C. preamplifier. Intracellular recordings of mechanosensory cells and motor neurons were made using sharp glass microelectrodes (15-20 $\mathrm{M} \Omega$ resistance, Sutter Instruments $\mathrm{P}-80$ micropipette puller) filled with $3 \mathrm{~m}$ potassium acetate and an Axoclamp 2A amplifier (Axon Instruments). Data from all recording devices was viewed on a storage oscilloscope (Tektronix) and converted for digital storage using a TL-1 analog/digital interface and pClamp 6.21 data acquisition program (Axon Instruments).

After setup, the preparation was allowed to recover for $\sim 30$ min before proceeding with the next stage of the experiment. The leech saline was replaced manually using a Pasteur pipette at $\sim 15$ min intervals throughout all subsequent experimental stages. Both the leech saline and the room in which all experiments were conducted was maintained at $\sim 24^{\circ} \mathrm{C}$.

\section{STIMULATION PARAMETERS}

The shortening response was stimulated by the delivery of a single 2-msec duration, capacitycoupled electroshock to the skin with the stimulation parameters controlled by a Grass S88 Stimulator and SIU5 Stimulus Isolation Unit. The intensity of the shock was determined by the minimum level that could elicit reliably a robust shortening response (5- to 15-nA range). This differs from previous experiments carried out with semi-intact leeches where the stimulus intensity was set within a predetermined range (Boulis and Sahley 1988; Ehrlich et al. 1992; Sahley et al. 1994). In those experiments one stimulus range was used during habituation training that activated only $\mathrm{T}$ and $\mathrm{P}$ cells, whereas a second, stronger stimulus range that activated $\mathrm{T}, \mathrm{P}$, and $\mathrm{N}$ cells was used to deliver sensitizing and dishabituating stimuli (Sahley et al. 1994). In this more reduced preparation the stimulus intensity necessary just to elicit a shortening response for habituation training was strong enough to activate $\mathrm{N}$ as well as $\mathrm{T}$ and $\mathrm{P}$ cells (see Results). The behavioral thresholds were determined separately for each of the stimulation sites $\left(\mathrm{S}_{\mathrm{T}}, \mathrm{S}_{\mathrm{N}}\right.$, and the dishabituating site) and were set so that each site elicited a shortening response of approximately the same magnitude. After determination of the stimulus levels at all three sites, the preparation was allowed to rest for $\sim 15-20 \mathrm{~min}$ before training commenced.

\section{TRAINING PROCEDURE}

The training protocol used in these experiments is summarized in Figure 3. Before training at the $S_{T}$ site the baseline shortening response at the $\mathrm{S}_{\mathrm{N}}$ site was determined [baseline $=$ average response across three trials, 2-min intertrial interval (ITI)]. Two minutes after the last $\mathrm{S}_{\mathrm{N}}$ baseline trial, habituation training was carried out at the $S_{\mathrm{T}}$ site using the protocol outline by Sahley et al. $(1994 ; 20$ trials, one pulse per trial, 2-min ITI). Data from 20 training trials were averaged into four and five trial blocks. The first block (consisting of trials 1-5) was

$$
\begin{array}{llllllllllllllll}
\hline & E & A & R & N & I & N & G & \mathbf{Q} & M & E & M & O & R & Y \\
407 & & & & & &
\end{array}
$$




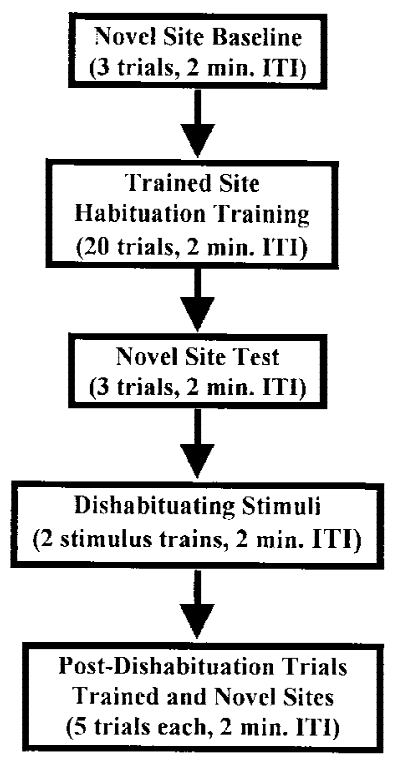

Figure 3: Diagram summarizing the training procedures used to test generalization of habituation.

used as the baseline for the subsequent responses elicited at $\mathrm{S}_{\mathrm{T}}$. After habituation training at $\mathrm{S}_{\mathrm{T}}$, the behavioral response at the $S_{N}$ site was probed for generalization of habituation (as with the baseline, the average response across three trials). The preparation was then dishabituated at the $S_{\mathrm{DH}}$ site by delivering two trains of 10 shocks (2-msec pulse duration, $10 \mathrm{~Hz}, 2$-min ITI). After delivery of the dishabituating stimuli the behavioral responses at both $S_{T}$ and $S_{N}$ were retested (five trials each at $S_{T}$ and $S_{N}, 2$-min ITI).

After habituation and dishabituation training, the level of sensory overlap between $S_{T}$ and $S_{N}$ was determined. Sensory overlap was measured as a proportion of preparations in which a mechanosensory cell was stimulated by both the $\mathrm{S}_{\mathrm{T}}$ and $\mathrm{S}_{\mathrm{N}}$ sites divided by the number of times that that cell was activated by one site or the other. For example, the G8 lateral $T$ cell in the ventral/dorsal group was stimulated by $S_{T}$ or $S_{\mathrm{N}}$ in nine different preparations and of these was stimulated by both sites in six preparations, yielding a sensory overlap value of $67 \%$. Activity from the T, P, and $\mathrm{N}$ cells in segmental ganglia 7-9 was recorded intracellularly, while the $S_{T}$ or $S_{N}$ site was stimulated, providing a quantitative measure of the level similarity between the $S_{T}$ and $S_{N}$ at the level of the primary afferents. These data were used to confirm that the positioning of $\mathrm{S}_{\mathrm{T}}$ and $\mathrm{S}_{\mathrm{N}}$ electrodes progressively closer to each other did result in greater levels of sensory overlap.
Experiments were carried out on four treatment groups and one control group. Each treatment group had a characteristic placement of the $S_{T}$ and $S_{N}$ pairs of electrodes and these electrode pairs were placed progressively closer across treatment groups (see Figs. 6-9, below, for electrode placement). Because the approximate distribution of mechanosensory receptive fields in the leech is known, it is possible to know a priori where on the skin to activate a certain set of sensory cells (e.g., dorsal vs. ventral afferents). Nevertheless, the mechanosensory cells activated by each skin electrode pair were confirmed by intracellular recordings after training. The treatment groups used in these experiments were, in order of level of sensory overlap, ventral/dorsal $(n=11)<$ ventral/lateral $(n=11)<$ posterior/anterior $(n=10)<$ overlapping $\left(\mathrm{S}_{\mathrm{T}}\right.$ and $\mathrm{S}_{\mathrm{N}}$ electrode pairs were placed as close to each other as possible; $n=10$ ). Preparations in the control group $(n=12)$ had electrodes implanted for habituation training and delivering dishabituation stimuli only and therefore, did not receive any extra stimulation associated with testing behavior at the $S_{N}$ site.

\section{STATISTICS}

For data analysis, the behavioral data from each trial block were normalized to the initial baseline response. In the case of $\mathrm{S}_{\mathrm{T}}$, the habituation and dishabituation trial blocks (trial block 2-5) were normalized to the first habituation training trial block. In the case of the $S_{N}$, data from the habituation generalization probe and dishabituation trial blocks (trial blocks 4 and 5, respectively) were normalized to the baseline trial block taken before habituation training at $S_{\mathrm{T}}$. Behavioral data were analyzed using a two-way analysis of variance (ANOVA) with repeated measures. Analysis was carried out using the Statistica (Statsoft, Inc.) statistics software package.

\section{Results}

\section{PROPERTIES OF THE QUASI-INTACT PREPARATION}

Behavioral changes during habituation and dishabituation training in the leech quasi-intact preparation were identical to that observed in intact and semi-intact preparations used by Sahley and coworkers, based on results obtained from the control group (Fig. 4; Boulis and Sahley 1988; Ehrlich et al. 1992; Sahley et al. 1994). Repeated electro-

$$
\begin{array}{lllllllllllllll}
L & E & A & R & N & I & N & G & \begin{array}{l}
\boldsymbol{Q} \\
408
\end{array} & M & E & M & O & R & Y
\end{array}
$$




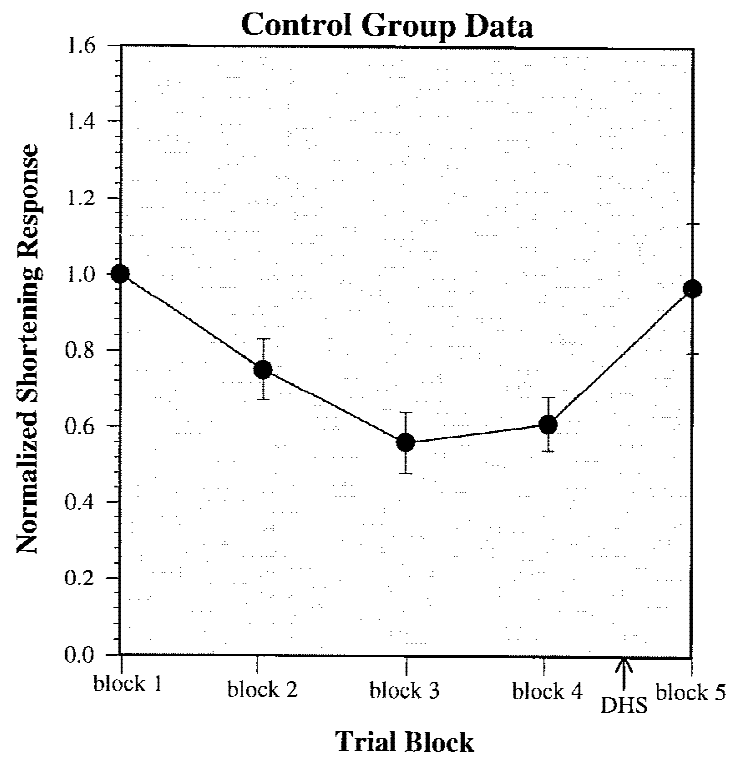

Figure 4: Changes in whole-body shortening behavior in the quasi-intact preparation from the control group during habituation training (trial blocks 1-4) and after the delivery of a strong dishabituating stimulus (trial block 5). Data have been normalized to the first trial block and have been presented as the mean \pm standard error. (DHS) Dishabituating stimulus.

shock stimulation at $S_{T}$ resulted in a decrease in the magnitude of whole-body shortening (trial blocks 1-4) and this response decrement could be reversed in trial block 5 after the presentation of a noxious stimulus at $\mathrm{S}_{\mathrm{DH}}$.

Activity from individual neurons known to participate in shortening are shown in Figure 5. The electroshock stimulus elicited a train of action potentials in the $\mathrm{T}$ cells, but only a single action potential in the $\mathrm{P}$ and $\mathrm{N}$ cells (Fig. 5A). Figure 5B provides an example of the activity in the S-interneuron and L-motorneuron during a stimulated shortening episode. The level of L-cell activity (mean \pm s.E. $=3.31 \pm 1.41 ; n=5$ ) was comparable, albeit somewhat lower, to what has been observed in other reduced preparations (Shaw and Kristan 1995) and the presence of L-cell activity six segments away, along with activity in the S cell, confirms that whole-body shortening was in fact the behavior being activated. Another observation from this trace involves the tight coupling of excitatory postsynaptic potentials (EPSP) and action potentials in the L cell with S-cell action potentials (Fig. 5B). The $S$ cell is known to make an excitatory electrical synapse onto the L cell (Magni and Pelligrino 1978) and the S cell may contribute to trans-
A
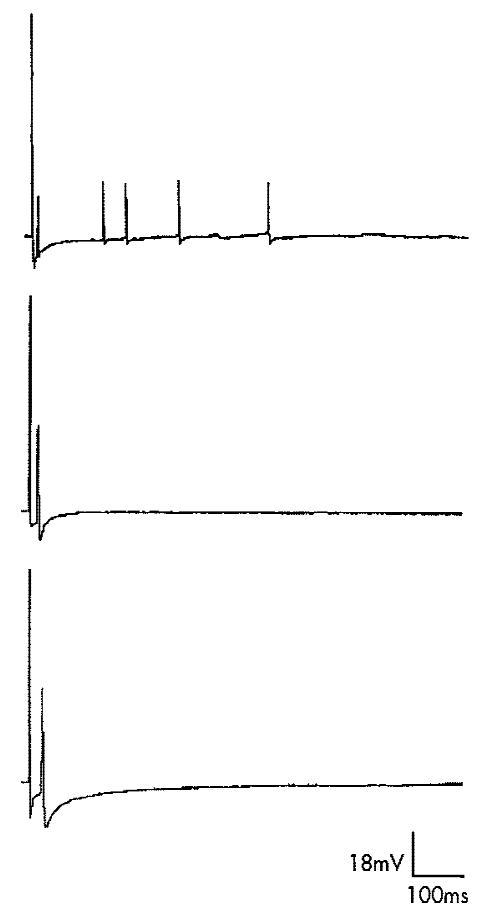

B

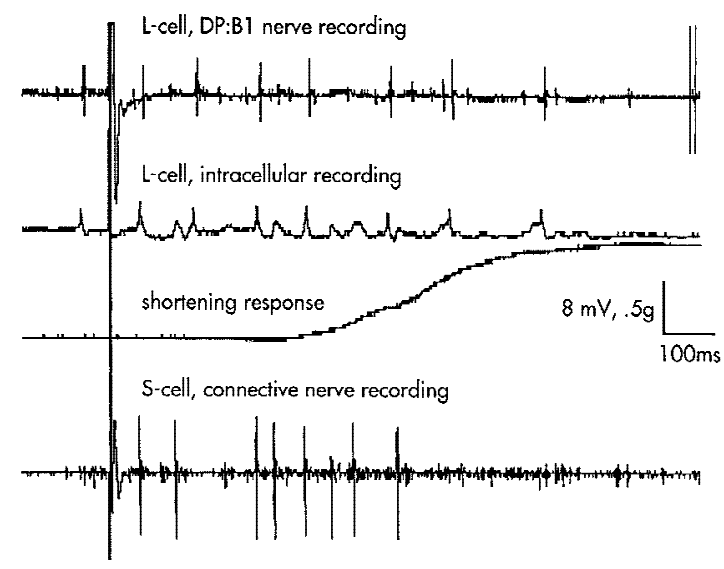

Figure 5: Sensory and motor properties of whole-body shortening in the quasi-intact preparation. (A) Intracellular recordings of activity evoked by stimulus sufficient to induce shortening in these preparations from T (top), $\mathrm{P}$ (middle), and $\mathrm{N}$ cells (bottom). (B) Simultaneous recording of stimulus-evoked neural and behavioral activity. The top two traces are extracellular and intracellular recordings respectively of the L-motor neuron in segment 14. The corresponding behavior recorded from a tension transducer is shown in the second from the bottom trace. The bottom trace is an extracellular record of $\mathrm{S}$ cell activity recorded from the VNC posterior of segment 15 . The notation next to the vertical calibration bar in $B$ corresponds to the $\mathrm{L}$ cell intracellular recording and the shortening response, respectively.

$$
\begin{array}{llllllllllllllll}
\hline & E & A & R & N & I & N & G & \mathbf{Q} & M & E & M & O & R & Y
\end{array}
$$


mitting shortening-inducing stimuli throughout the leech body (Shaw and Kristan 1995). Although Figure 5B demonstrates S-cell input onto an L cell several segments from the stimulus site, it should be noted that not all preparations exhibited a onefor-one correspondence between S- and L-cell impulses.

\section{SENSORY OVERLAP}

The placement of the electrode pairs in each of the treatment groups was effective at generating increasing degrees of sensory overlap in the ventral/dorsal, ventral/lateral, posterior/anterior, and overlapping groups (Figs. 6-9). In preparations where the $S_{\mathrm{T}}$ and $\mathrm{S}_{\mathrm{N}}$ electrodes were relatively far apart (e.g., the ventral/dorsal group; Fig. 6) the level of sensory overlap was low except in sensory cells whose receptive fields bordered the areas stimulated by both $\mathrm{S}_{\mathrm{T}}$ and $\mathrm{S}_{\mathrm{N}}$. As the electrode pairs were placed closer together, the level of sensory overlap increased in all of the afferent cells regard- less of whether the electrode pairs were placed bilaterally (e.g., the ventral/lateral group; Fig. 7), or unilaterally (e.g., the posterior/anterior and overlapping groups; Figs. 8 and 9). This pattern was seen both in the segment where the electrodes were implanted (G8) and in mechanosensory cells from adjacent segments (G7 and G9). The pattern of sensory overlap across the four treatment groups indicates that stimuli used in these experiments are capable of activating a distinct set of mechanosensory neurons depending on the placement of the electrodes. Although $\mathrm{N}$ cells were also tested in this manner, they are not included in this analysis as their receptive fields span the entire segment and as a result were stimulated by both $S_{T}$ and $S_{N}$ sites regardless of their placement.

\section{BEHAVIORAL DATA}

As seen in Figures 6-9 a second form of behavioral plasticity emerged besides habituation. In
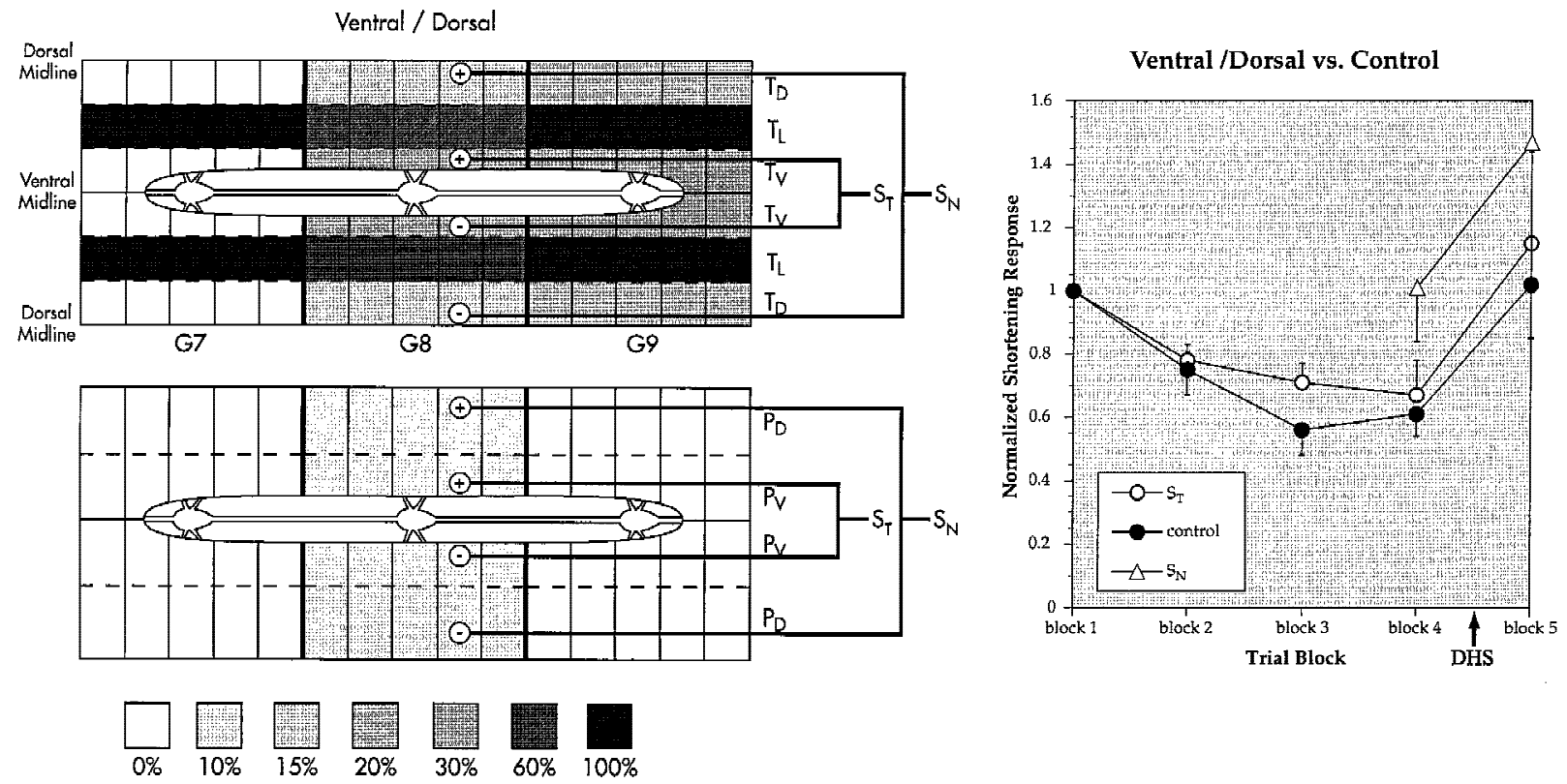

Figure 6: Sensory overlap and behavioral data from the ventral/dorsal group. (Left) The receptive fields of the touch (T) and pressure $(\mathrm{P})$ mechanosensory neurons across three segments are diagrammatically shown and the shading in each receptive field indicates the percentage of times that the corresponding sensory neuron was activated by both stimulation sites in the same preparation (values for each shade of gray are shown at the figure bottom). The subscripts D, L, and $\mathrm{V}$ stand for dorsal, lateral, and ventral respectively. The + and - symbols indicate the placement of the implanted electrodes for each site. (Right) The behavioral response elicited by the $S_{\mathrm{T}}$ site $(\mathrm{O})$ is habituated after repeated stimulations (blocks 1-4) and dishabituates after the delivery of a noxious stimulus several segments away (block 5). The shortening reflex elicited by the $S_{N}$ site $(\triangle)$ is unchanged from the baseline indicating no generalization of habituation. The control data $(\mathbf{O})$ are from control preparations where no $S_{N}$ site was used (see Fig. 3) and have been plotted in Figs. 4-7 as a comparison to the treatment groups.

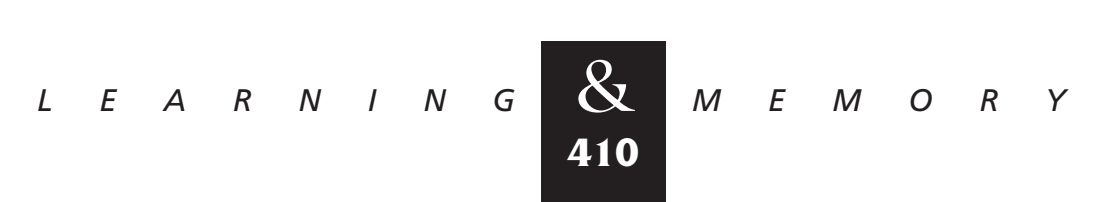



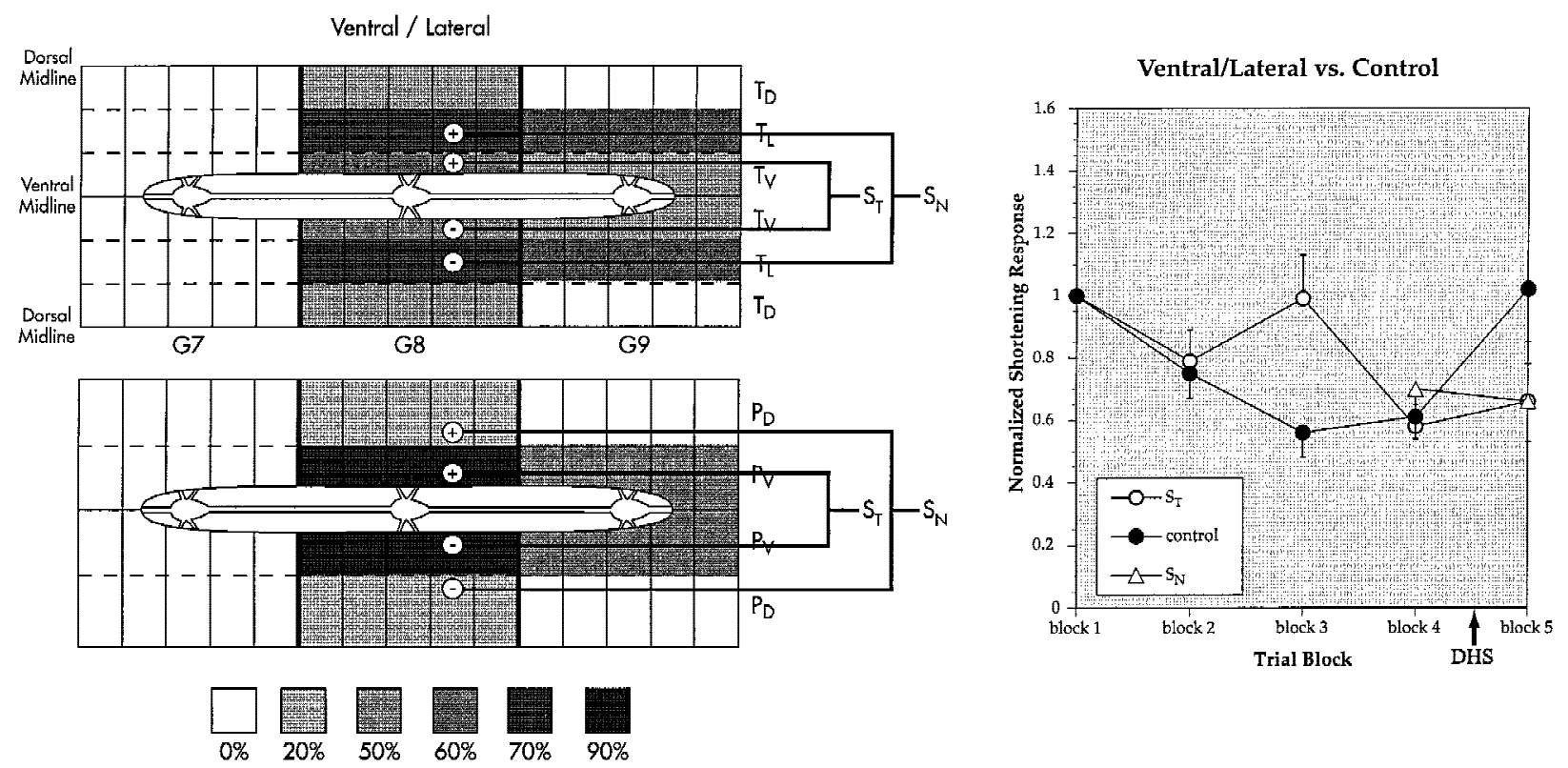

Figure 7: Sensory overlap and behavioral data from the ventral/lateral group. (Left) Same as Fig. 6. (Right) The $\mathrm{S}_{\mathrm{T}}$ behavior does habituate by trial block 4 , but the response at block 3 is substantially greater than in the control group. The behavior at the $S_{N}$ site has decreased significantly from the initial response, indicating generalization of habituation between these two sites.

preparations where there was little sensory overlap between $\mathrm{S}_{\mathrm{T}}$ and $\mathrm{S}_{\mathrm{N}}$, such as in the ventral/ dorsal group, there was a substantial decrease in the behavioral response elicited at $\mathrm{S}_{\mathrm{T}}$ after habituation training (Fig. 6) and the level of habituation was virtually identical to that observed in the con-
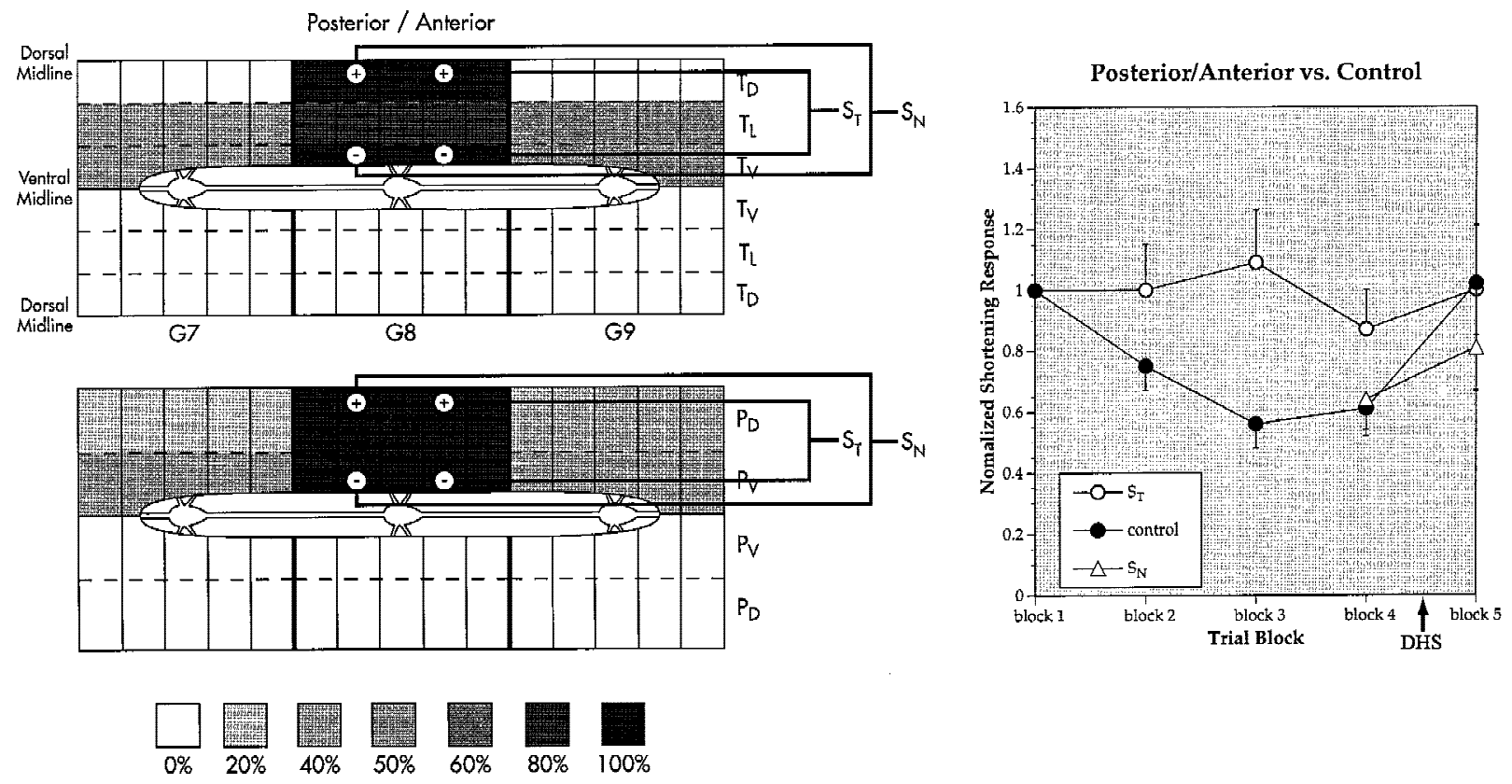

Figure 8: Sensory overlap and behavioral data from the posterior/anterior group. (Left) Same as Fig. 6. (Right) The shortening reflex elicited by $S_{T}$ does not habituate after repeated stimulations. The reflex elicited by $S_{N}$ does decrease significantly relative to its baseline indicating that the operational habituation training applied to $S_{\mathrm{T}}$ did generalize to $S_{\mathrm{N}}$.

$$
\begin{array}{lllllllllllllll}
L & E & A & R & N & I & N & G & \boldsymbol{\bigotimes} & M & E & M & O & R & Y \\
\mathbf{4 1 1} & & & & & &
\end{array}
$$



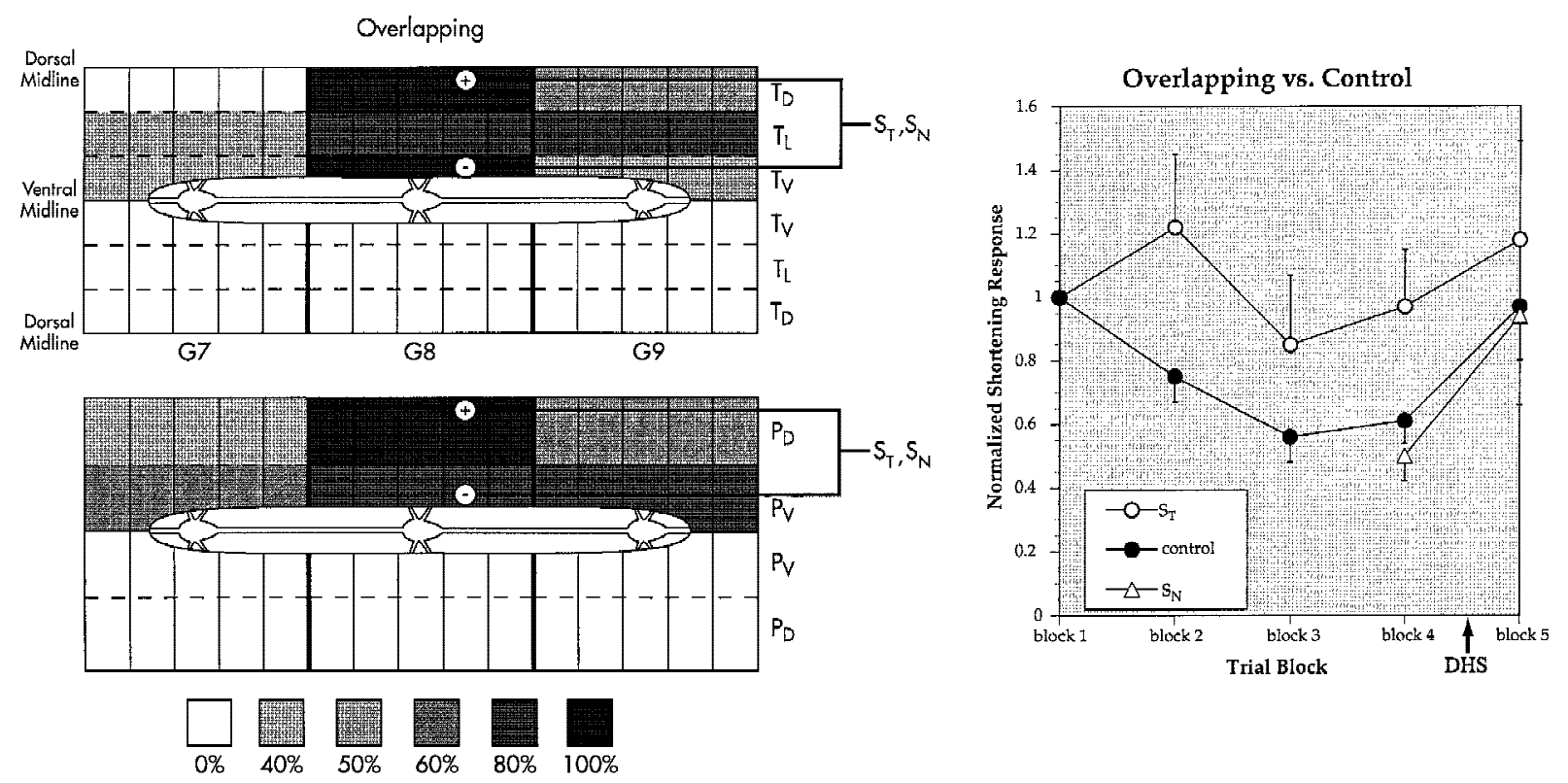

Figure 9: Sensory overlap and behavioral data from the overlapping group. (Left) Same as Fig. 6. (Right) The shortening reflex elicited by $S_{T}$ does not habituate after repeated stimulations. The reflex elicited by $S_{N}$ does decrease significantly relative to its baseline indicating that the operational habituation training applied to $S_{T}$ did generalize to $S_{N}$.

trol group (see Fig. 4). However, in preparations from the posterior/anterior and overlapping groups, where the level of sensory $\mathrm{S}_{\mathrm{T}} / \mathrm{S}_{\mathrm{N}}$ overlap was high, the magnitude of the shortening reflex elicited at $\mathrm{S}_{\mathrm{T}}$ was unchanged from the baseline after habituation training (Figs. 8 and 9). Preparations from the treatment group that had an intermediate level of sensory overlap, the ventral/lateral group, were also intermediate in terms of the change in $\mathrm{S}_{\mathrm{T}}$-elicited shortening after habituation training (Fig. 7). Although this group did habituate (see difference between trial blocks 1 and 4), the shortening response level during trial block 3 was greater than in the corresponding trial blocks in groups where normal habituation occurred.

It appears that stimulation of $\mathrm{S}_{\mathrm{N}}$ before habituation training at $S_{T}$ induced a behavioral facilitation process that prevented normal habituation at $S_{T}$ when there was sufficient sensory overlap between the two stimulation sites. (Stimulation of $S_{N}$ before $S_{\mathrm{T}}$ habituation training was done to obtain a baseline response level for the shortening reflex.) This conclusion was confirmed by a two-way ANOVA that revealed a statistically significant interaction effect of treatment group (placement of $\mathrm{S}_{\mathrm{N}}$ electrodes relative to $\mathrm{S}_{\mathrm{T}}$ ) and habituation training on $\mathrm{S}_{\mathrm{T}}$-elicited behavior (behavioral response of trials $1-4)\left(F_{\text {inter }}=2.14, P \leqslant 0.05\right.$, df $\left.=12\right)$. Although there was not a significant effect attribut- able to treatment group alone $\left(F_{\text {treat }}=2.48\right.$, $P \geqslant 0.05$, df $=4)$, there was a statistically significant effect of training trial $\left(F_{\text {trial }}=7.29, P \leqslant 0.001\right.$, $\mathrm{df}=3$ ). Posthoc analysis (LSD test) indicated that there was a significant decrease in the behavioral responses from trial block 4 relative to those at trial block 1 in the control, ventral/dorsal, and ventral/ lateral groups $(P \leqslant 0.05)$, whereas no significant change in behavior was detected in the posterior/ anterior and overlapping groups $(P>0.05)$. A twoway ANOVA that examined the effects of treatment group and dishabituating stimuli (trial block 4 vs. 5) detected a significant trial effect $\left(F_{\text {trial }}=6.80, P \leqslant 0.05, \mathrm{df}=1\right)$, but no effect attributable to treatment $\left(F_{\text {treat }}=1.35, P>0.05, \mathrm{df}=4\right)$ or treatment/trial interaction $\quad\left(F_{\text {inter }}=0.62\right.$, $P>0.05$, df $=4)$. To summarize, the data clearly show that the ability of a preparation to carry out habituation in this training paradigm was dependent on the proximity of the $S_{N}$ and $S_{T}$ sites.

Generalization of habituation from $S_{T}$ to $S_{N}$ was observed in all but the ventral/dorsal treatment groups (Figs. 6 to 9). Two-way ANOVA indicated that there was a significant decrease in the magnitude of the $S_{\mathrm{N}}$ response at trial block 4 relative to the initial baseline $\left(F_{\text {trial }}=19.78, P \leqslant 0.0001\right.$, df $=1$ ). Post-hoc analysis (LSD) showed a statistically significant decrease in the $S_{N}$ response in the ventral/lateral, anterior/posterior, and overlapping

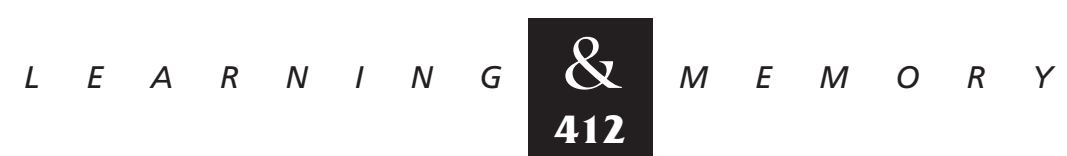


groups, but not the ventral/dorsal group, after habituation training at $\mathrm{S}_{\mathrm{T}}$. This change in the behavior elicited at $S_{N}$ was dependent on the relative positions of the $\mathrm{S}_{\mathrm{T}}$ and $\mathrm{S}_{\mathrm{N}}$ electrodes $\left(F_{\text {treat }}=2.88\right.$, $P \leqslant 0.05, \quad$ df $=3 ; F_{\text {inter }}=2.88, P \leqslant 0.05, \quad \mathrm{df}=3$ ). However, generalization of habituation at $S_{N}$ was apparently not dependent on the actual habituation of $\mathrm{S}_{\mathrm{T}}$-elicited behavior, but only on the operational habituation at $\mathrm{S}_{\mathrm{T}}$ as no habituation at this site was observed in the posterior/anterior and overlapping groups. Testing for dishabituation at the $\mathrm{S}_{\mathrm{N}}$ site, a two-way ANOVA indicated a significant increase in shortening between trial blocks 4 and 5 $\left(F_{\text {trial }}=4.94, P \leqslant 0.05, \mathrm{df}=1\right)$. The changes in trial block $4-5$ behavior were not affected by the placement of the $\mathrm{S}_{\mathrm{T}}$ and $\mathrm{S}_{\mathrm{N}}$ electrodes $\left(F_{\text {treat }}=2.00\right.$, $P>0.05, \mathrm{df}=3 ; F_{\text {inter }}=1.09, P>0.05$, df $\left.=3\right)$. An additional group of preparations were tested to confirm that observed changes in shortening were in fact attributable to habituation training. Quasiintact preparations stimulated at a single site on the skin, at the beginning and end of a 40-min period to reproduce the time course of habituation training without the repetitive stimulations, showed no changes in behavior (paired $t=1.50, P>0.05$. df $=3$; data not shown).

To assess the duration of this behavioral facilitation, the overlapping experiment shown in Figure 9 was repeated, except that a 10-min delay period was interposed between the $S_{N}$ baseline trials and the start of $\mathrm{S}_{\mathrm{T}}$ habituation training (data not shown). The $\mathrm{S}_{\mathrm{T}}$ response from this delay group ( $n=12$ ) did not differ from the overlapping group, $\mathrm{S}_{\mathrm{T}}$-elicited behavior did not decrease during habituation training, indicating that facilitating effect had not yet decayed $\left(F_{\text {trial }}=1.11, P>0.05, \mathrm{df}=1\right.$; $F_{\text {treat }}=0.02, \quad P>0.05, \quad \mathrm{df}=3 ; \quad F_{\text {inter }}=0.29$, $P>0.05$, df $=3$ ). Generalization of habituation at $\mathrm{S}_{\mathrm{N}}$ was also observed in the delay group and did not differ from the overlapping group in this respect either $\left(F_{\text {trial }}=21.74, \quad P \leqslant 0.001, \quad \mathrm{df}=1\right.$; $F_{\text {treat }}=0.66, \quad P>0.05, \quad \mathrm{df}=1 ; \quad F_{\text {inter }}=0.66$, $P>0.05$, df $=1$ ).

\section{Discussion}

Different types of learning exhibit different levels stimulus discrimination as is illustrated by the degree to which trained stimuli generalize to a subsequently presented novel stimulus. Classical conditioning and habituation are relatively stimulus specific and generalize only to very similar novel stimuli (Mackintosh 1974; Stopfer et al. 1996; but see Krasne and Teshiba 1995), whereas sensitization generalizes to nearly all potential novel stimuli (Carew et al. 1971; Boulis and Sahley 1988; Davis 1989; Lockery and Kristan 1991). Using a quasi-intact preparation of the medicinal leech the level of generalization of habituation of the whole-body shortening response between two positionally distinct skin stimulation sites was observed. As expected, stimulation sites that were closer to each other and shared a larger proportion of the same mechanosensory neurons exhibited generalization of habituation. Unexpectedly, the training protocol used to observe generalization of habituation at $S_{N}$ produced a second, facilitating form of behavioral plasticity at $\mathrm{S}_{\mathrm{T}}$. This facilitating process showed a high degree of stimulus specificity because it was observed at $\mathrm{S}_{\mathrm{T}}$ at the same time that habituation was present in $\mathrm{S}_{\mathrm{N}}$-elicited behavior.

\section{PROPERTIES OF THE QUASI-INTACT PREPARATION}

The behavior observed in the quasi-intact preparation generally conforms with the wholebody shortening observed in intact and semi-intact leeches. One difference is the greater stimulus intensities needed to initiate whole-body shortening. In other preparations, stimulation of $\mathrm{T}$ and $\mathrm{P}$ cells across two receptive fields is sufficient to elicit whole-body shortening (Boulis and Sahley 1988; Shaw and Kristan 1995), whereas in quasi-intact preparations, activation of the $\mathrm{N}$ cells was required as well. The reason for the greater stimulation may be attributable to the more reduced nature of the preparation. Alternatively, the reason could involve inhibitory input from proprioceptive elements of the nervous system attributable to the pinning of the preparation, which prevents a substantial portion of the animal from moving. Stretch receptors are present in the leech skin (Blackshaw and Thompson 1988) and such proprioceptive input is known to modify leech swimming behavior (C.G. Hocker and W.O. Friesen; X. Yu and W.O. Friesen; both unpubl.). Nevertheless, we believe that the observed behavior can be classified as whole-body shortening and does not differ substantially from the behavior that would be observed in an intact leech because (1) $\mathrm{N}$ cells can be activated by stimuli that induce shortening (Shaw and Kris$\tan 1995)$; (2) the number and type of sensory neurons activated by the stimulus and the level of activity by the L-motorneuron and the S-interneuron

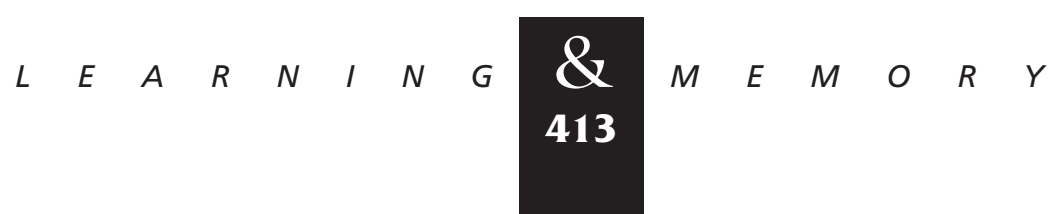


resemble the neural activity observed in other preparations; and (3) control group behavior during habituation and dishabituation training is similar to behavioral results obtained from intact and semi-intact leeches (Boulis and Sahley 1988; Sahley et al. 1994).

\section{GENERALIZATION OF HABITUATION}

The level of generalization of habituation in the leech whole-body shortening response was dependent on how close the $S_{N}$ electrodes were to the $S_{\mathrm{T}}$ electrodes. This was in large part attributable to the proportion of mechanosensory cells shared by both stimulation sites, based on the experimental groups in which generalization was observed (ventral/lateral, posterior/anterior, and overlapping groups, but not the ventral/dorsal group). This is consistent with experiments in Aplysia (Stopfer et al. 1996) where generalization of habituation would occur between two nearby training sites, but not between two sites on opposite sides of the animal. In contrast, in the crayfish escape response, habituation could generalize between two bilaterally separated stimulation sites that shared no primary afferents (Krasne and Teshiba 1995). In the leech it appears that a moderate level of sensory overlap was sufficient to support generalization of habituation given that generalization was observed in a group that had a lower proportion of shared sensory cells (ventral/ lateral) as compared to the other two training groups. Thus, generalization may not be attributable to general sensory overlap, but rather to overlap of a specific cell type, namely the $\mathrm{P}$ cells. Whole-body shortening requires stimulation across two P-cell receptive fields (Shaw and Kristan 1995) and when two stimulation sites shared at least one $P$ cell, generalization could take place. This is supported by experiments in another defensive behavior in the leech, local bending, which have shown that the level of activity in different $P$ cells can communicate effectively the position of a mechanosensory stimulus as a result of the connections between the P cells and a network of interneurons that are part of local bending circuit (Lockery and Kristan 1990a,b; Lewis and Kristan 1998). It is possible that positional information of stimuli inducing whole-body shortening is processed by a similar sensory processing network.

In the posterior/anterior and overlapping groups, where generalization of habituation was observed, habituation was observed only at the $S_{N}$ site and not at the $S_{\mathrm{T}}$ site. The reason for this lack of habituation at $S_{\mathrm{T}}$ appears to involve a novel mechanism of behavioral facilitation, which will be discussed more fully below. Nevertheless, the data show that the neural processes underlying habituation cannot exclusively involve a depression in signaling along monosynaptic pathways between sensory to motor or interneuron connections (Hawkins et al. 1993). This model would predict that any time generalization of habituation was observed at $S_{\mathrm{N}}$ as a result of sharing mechanosensory cells with $\mathrm{S}_{\mathrm{T}}$, habituation should also be seen at $\mathrm{S}_{\mathrm{T}}$. This was not the case in our experiments indicating that habituation is mediated, at least in part, by heterosynaptic pathways. Krasne and Teshiba (1995) have shown that habituation of the crayfish escape response is largely dependent on a descending inhibitory input outside of the direct stimulusresponse pathway. Goldberg and Lukowiak (1984) observed a decrease in the Aplysia siphon withdrawal response after habituation of the gill withdrawal reflex, indicating the presence of a heterosynaptic inhibition during habituation. Furthermore, experiments on habituation of the tail and siphon withdrawal reflexes in Aplysia showed an increase in heterosynaptic epsp's at the sensory-tomotor synapse instead of homosynaptic depression (Stopfer and Carew 1996), providing additional evidence for the presence of a heterosynaptic process for habituation in invertebrates.

An alternative interpetation of the changes in $\mathrm{S}_{\mathrm{N}}$-induced shortening is that habituation transferred from the $S_{T}$ to the $S_{N}$ stimulus-response pathway. This provides a potential explanation for how $\mathrm{S}_{\mathrm{N}}$-induced shortening could undergo habituation, whereas behavior at $S_{\mathrm{T}}$ remained unchanged (as in the posterior/anterior and overlapping groups). As mentioned above, Goldberg and Lukowiak (1984) observed transfer of habituation of the gill withdrawal reflex to the siphon withdrawal response, although these two structures do not appear to share any sensory units [in contrast to the results of Stopfer and Carew (1996)]. However, we still believe that generalization of habituation from $S_{T}$ to $S_{N}$ remains the more likely explanation. Habituation at $S_{\mathrm{N}}$ did depend on increasing sensory overlap with $S_{T}$ and habituation of both $S_{T}$ and $S_{N}$ was observed in one of the experimental groups (ventral/lateral). Although generalization of habituation at $S_{N}$ in the absence of habituation at $S_{T}$ is surprising, we believe that this can be explained by the behavioral facillatory process described below.

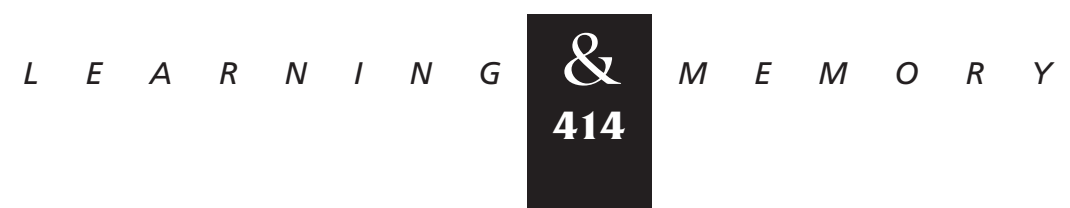


AN INTRINSIC PROCESS CONTRIBUTING TO SENSITIZATION

Interestingly, in groups where both sites shared all or nearly all the same mechanosensory cells, two opposite forms of behavioral plasticity, habituation at $S_{N}$ and a facilitating process at $S_{T}$, were observed. Furthermore the extent of habituation at $S_{\mathrm{T}}$ was attributable to the proximity of the $\mathrm{S}_{\mathrm{T}}$ electrodes to the $\mathrm{S}_{\mathrm{N}}$ electrodes. That is habituation at $S_{T}$ was not affected when there was little sensory overlap between $S_{\mathrm{N}}$ and $S_{\mathrm{T}}$, but when the level of sensory overlap was high, habituation was prevented at $S_{T}$ in such a way that did not affect generalization of habituation to $\mathrm{S}_{\mathrm{N}}$.

Preparations with little sensory overlap between $S_{T}$ and $S_{N}$, such as the ventral/dorsal group, underwent normal habituation at $\mathrm{S}_{\mathrm{T}}$, whereas those with substantial overlap, the anterior/posterior and overlapping groups, did not habituate. The group with an intermediate level of sensory overlap (ventral/lateral) did undergo habituation at $\mathrm{S}_{\mathrm{T}}$, but here too the behavioral pattern during habituation training was different from that observed in the ventral/dorsal or control groups. The pattern of $\mathrm{S}_{\mathrm{T}}$ behavior during habituation training in the overlapping and posterior/anterior groups resembles sensitization of the leech whole-body shortening reflex (Boulis and Sahley 1988; Ehrlich et al. 1992; Sahley et al. 1994). Sensitization of this behavior is characterized, in part, by a failure to habituate to repeated stimulations and is induced by the delivery of a substantially stronger electroshock stimulus delivered several segments away from the test stimulus. In the current experiments we observed a similar phenomenon, a failure of $\mathrm{S}_{\mathrm{T}}$-elicited shortening to habituate, although no explicit sensitizing stimulus had been presented. Instead these preparations received stimulation within the same segment (the $\mathrm{S}_{\mathrm{N}}$ site) before training of a magnitude that was similar to the stimulus used at $\mathrm{S}_{\mathrm{T}}$ site.

Although phenomenologically similar, this form of behavioral facilitation is distinct from traditional sensitization. Sensitization is normally induced by a strong stimulus that differs in terms of modality or intensity from the test stimulus used to elicit the behavior of interest (Boulis and Sahley 1988; Davis 1989). However, in our case the stimuli applied at $S_{N}$ were approximately equivalent both in magnitude and position to $S_{\mathrm{T}}$ and would not be expected to induce sensitization. Second, the facilitating effect of a sensitizing stimu- lus is the same regardless of where that stimulus is applied. In these experiments, the strength of the observed facilitating effect was determined by the proximity of the $S_{N}$ site to the $S_{T}$ site (see Figs. 6-9). Third, the facilitating effect of traditional sensitization generalizes to all subsequent behavioral responses, something that was not seen with the $\mathrm{S}_{\mathrm{N}}$-induced behavioral facilitation. In groups where habituation at $\mathrm{S}_{\mathrm{T}}$ did not occur (posterior/anterior and overlapping), the $\mathrm{S}_{\mathrm{N}}$-elicited behavior still underwent habituation as a result of the habituation training at $S_{\mathrm{T}}$ (see trial block 4 in Figs. 8 and 9). However, the behavioral facilitation observed at $\mathrm{S}_{\mathrm{T}}$ was not observed at $S_{\mathrm{N}}$ indicating that generalization is not characteristic of this form of sensitization.

Davis and File (1984) have stated that habituation and sensitization can occur as a result of both intrinsic and extrinsic neurophysiological processes. An intrinsic process would involve modulation that occurred within the stimulus-response pathway of the behavior of interest, whereas an extrinsic process would involve modulation from neural components outside of that pathway. Habituation is thought traditionally to occur by way of an intrinsic mechanism (Castellucci et al. 1970; Thompson et al. 1973; but see Krasne and Teshiba 1995). Sensitization, on the other hand, is generally believed to be an extrinsic process involving the activity of modulatory interneurons that are activated by a sensitizing stimulus, but not part of a stimulus-response neural pathway being tested (Thompson et al. 1973; Castellucci and Kandel 1976; Byrne et al. 1978; Hawkins et al. 1981). Evidence of an extrinsic mechanism contributing to habituation has been observed in the crayfish (Krasne and Teshiba 1995), Aplysia (Goldberg and Lukowiak 1984; Stopfer and Carew 1996), and the data presented here, but no indication of the intrinsic sensitization process hypothesized by Davis and File (1984) has been reported. It would appear that the behavioral facilitation that we have seen in the leech-shortening response represents an observable form of intrinsic sensitization. The sensitization effect is specific to a single stimulus-response pathway $\left(\mathrm{S}_{\mathrm{T}}\right)$ is induce by stimulation of a site on the leech body wall $\left(\mathrm{S}_{\mathrm{N}}\right)$ that shares most of the same sensory neurons as $\mathrm{S}_{\mathrm{T}}$, and can be observed at $S_{T}$ while $S_{N}$ is in a habituated state. It should be stressed that intrinsic sensitization is not, by itself, a form of nonassociative learning. Intrinsic sensitization is a behavioral facilitating process that contributes (along with extrinsic mechanisms)

$$
\begin{array}{lllllllllllllll} 
& E & A & R & N & I & N & G & \begin{array}{l}
\boldsymbol{Q} \\
415
\end{array} & M & E & M & O & R & Y
\end{array}
$$


to the nonassociative learning known as sensitization.

There is a precedent for behavioral facilitation occurring without presentation of an explicit sensitizing stimulus. Incremental (Razran 1971) or wind-up sensitization (Hinde 1970) is a form of behavioral facilitation generated during the initial stages of habituation training (Davis and Wagner 1969; Groves et al. 1970; Lockery and Kristan 1991). This form of behavioral facilitation occurs as a result of activating a single stimulus-response pathway and not attributable to the presentation of a different sensitizing stimulus. It has been suggested that such behavioral facilitation reflects an initial incremental process that decays because of an independent, slower developing decremental or habituating process, as predicted by dual-process theory (Thompson et al. 1973). It is possible that, as with the intrinsic sensitization observed here, the behavioral facilitation that occurs during incremental sensitization is the result of an intrinsic sensitizing process activated in the absence of the extrinsic processes that would normally also contribute to sensitization.

Recently, it has been recognized that neuromodulation can occur intrinsically as well as extrinsically (for review, see Katz and Frost 1996). Extrinsic modulation is thought to be ubiquitous and involves the modification of a neural circuit through the release of neuromodulators from neurons not part of the circuit being activated (HarrisWarrick 1991). Intrinsic modulation is believed to be the result of neuromodulators released by neurons within the circuit itself (Katz and Frost 1996). Modulatory transmitters are coreleased with standard neurotransmitters by a neuron within a given circuit, altering the response of a target neuron or muscle to signals from the modulatory cell or from another neuron within the circuit. Intrinsic neuromodulation has been observed to modify behavior at the neuromuscular junction (Cropper et al. $1987,1990)$ and central pattern generator (CPG) level (Whim and Lloyd 1989; Cropper et al. 1990; Meyrand et al. 1991; Weiss et al. 1992; Katz and Frost 1995, 1996). Intrinsic modulation is precisely the sort of physiological mechanism that Davis and File (1984) described as likely to mediate intrinsic sensitization. Facilitation of a specific stimulus-response circuit requires that the modulatory process occurs within the activated circuit. Extrinsic modulation, on the other hand, would facilitate inactive as well as active stimulus-response pathways. A simplified, hypothetical model of how in- trinsic and extrinsic modulatory processes would differentially contribute to sensitization is presented in Figure 10.

Now that a protocol has been developed to behaviorally isolate the processes that mediate intrinsic and extrinsic sensitization, it is necessary to characterize the neurophysiological mechanisms that distinguish intrinsic from extrinsic sensitization. Extrinsic sensitization of the leech wholebody shortening reflex is dependent on serotonin (5HT) released from the Retzius cell and the serotonergic system can be selectively lesioned by treating animals with the toxin 5,7-dihydroxytryptamine (5,7-DHT) (Ehrlich et al. 1992). Leeches treated with 5,7-DHT are unable to undergo sensi-
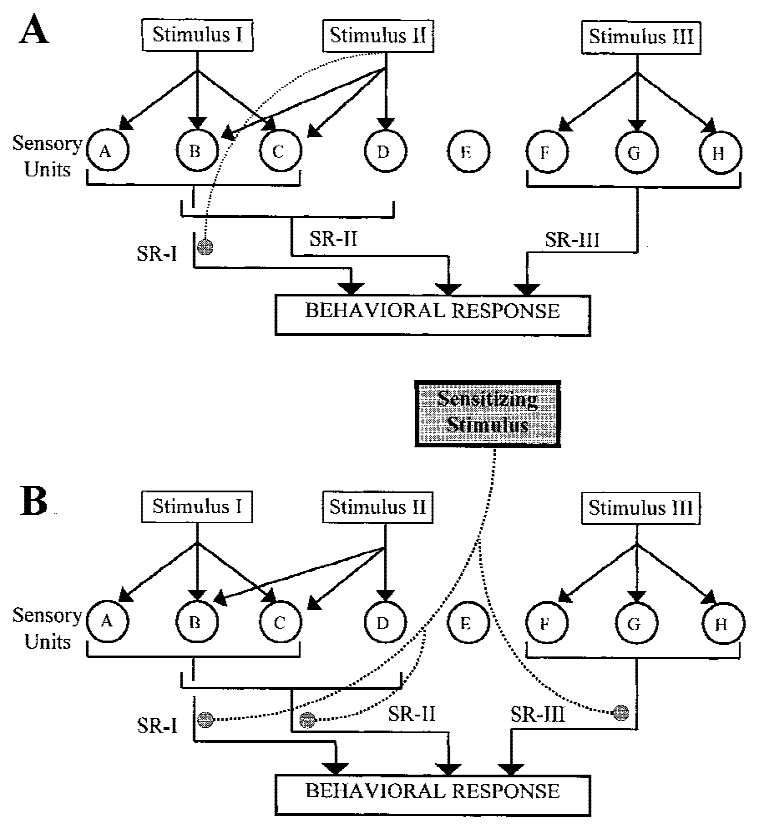

Figure 10: Intrinsic versus extrinsic mechanisms of sensitization. On the basis of activation patterns of the sensory units, each stimulation site has a unique stimulus-response pathway (SR-). In this diagram all three stimuli converge to generate the same behavior, but stimulus III could alternatively produce a completely different behavior from stimuli I and II. (A) Stimulation at II induces intrinsic sensitization in I (indicated by the dotted line and shaded circle) because there is considerable sensory overlap between I and II. Intrinsic sensitization is not induced in III because there is no sensory overlap between II and III. (B) Extrinsic sensitization is induced by a qualitatively different stimulus (sensitizing stimulus) that has no sensory units in common with stimulus I, II, or III. The sensitization produced by this process affects all three stimulus-response pathways (indicated by the dotted lines and shaded circles).

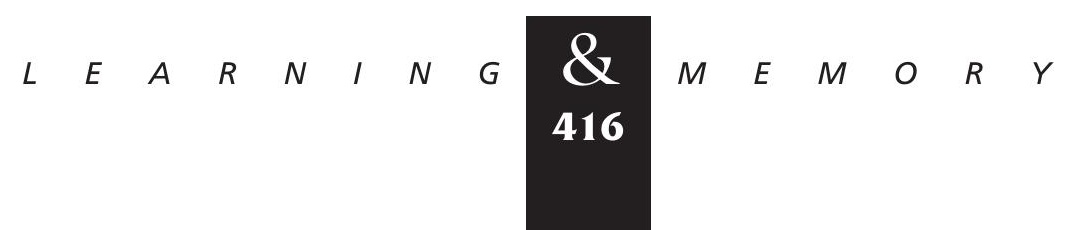


tization, but the ability to carry out whole-body shortening is not affected. It is reasonable to hypothesize that $5 \mathrm{HT}$ dependence is one feature that distinguishes extrinsic from intrinsic sensitization and that 5HT-depleted animals will still be able to undergo intrinsic sensitization if this facilatory process is not dependent on Retzius cell-released 5HT. These experiments are currently underway. Although an intrinsic modulatory process has yet to be identified in the leech whole-body shortening reflex, a potential candidate is the S-interneuron because (1) the $S$ cell is active during whole-body shortening and contributes to plasticity of this behavior (Sahley et al. 1994; Shaw and Kristan 1995; Modney et al. 1997); and (2) the S cell contains the modulatory peptide myomodulin (Keating and Sahley 1996). Because it is possible to disrupt the $S$ cell chain by selectively cutting the $\mathrm{S}$ cell axon (Mason and Muller 1996; Modney et al. 1997), an interesting experiment would be to induce intrinsic sensitization in S cell axotomized leeches to determine whether intrinsic sensitization is dependent on an intact chain of S cells.

\section{CONCLUSIONS}

The data presented demonstrate that habituation and sensitization, supposedly simple forms of learning, are in fact quite complex. Habituation of the leech whole-body shortening reflex is mediated, at least in part, by heterosynaptic processes and generalization of habituation can occur when two stimuli share at least one of the two P cells required to initiate the behavior. In addition, an intrinsic facilitating process that contributes to sensitization was observed that potentiated the behavior elicited from a single stimulus-response pathway. This intrinsic sensitizing process was specific enough to prevent habituation at the site of training, even when habituation could be observed at a nearby untrained site as a result of generalization. Understanding the neural basis of intrinsic sensitization could help clarify the physiological processes of associative learning. Extrinsic sensitization processes have been shown to contribute to associative learning both in the leech (Sahley 1994) and in Aplysia (Hawkins et al. 1993), but the stimulus discrimination properties of associative learning and sensitization are very different. In associative learning, the learned behavioral response is fairly specific to the trained stimulus, therefore the level of generalization is relatively low. Extrinsic sensitization, however, alters the behavioral re- sponse to nearly all subsequent stimuli and therefore, the level of generalization is quite high. It is possible that intrinsic sensitization provides a facilitating process specific to a single stimulus-response pathway that contributes to the associative learning. This does not discount the potential role of extrinsic sensitization in associative learning, but instead suggests that there are both intrinsic and extrinsic facilitating processes that contribute to sensitization and excitatory conditioning.

\section{Acknowledgments}

We thank Ken Muller and three anonymous reviewers for their helpful suggestions and Rodney McPhail for figure illustrations and graphics. This research was supported by National Institutes of Health grants F32-NS10065 (B.D.B.) and R01-MH44789 (C.L.S.).

The publication costs of this article were defrayed in part by payment of page charges. This article must therefore be hereby marked "advertisement" in accordance with 18 USC section 1734 solely to indicate this fact.

\section{References}

Bagnoli, P., M. Brunelli, and F. Magni. 1972. A fast conducting pathway in the central nervous system of the leech Hirudo medicinalis. Arch. Ital. Biol. 110: 35-51.

Blackshaw, S.E. and S.W. Thompson. 1988. Hyperpolarizing responses to stretch in sensory neurons innervating the leech body wall muscle. J. Physiol. 396: 121-137.

Boulis, N. and C. Sahley. 1988. A behavioral analysis of habituation and sensitization of shortening in the semi-intact leech. J. Neurosci. 8: 4621-4627.

Byrne, J.H., V.F. Castellucci, and E.R. Kandel. 1978. Contribution of individual mechanoreceptor neurons mediating defensive gill-withdrawal in Aplysia. J. Neurophys. 41: 418-431.

Carew, T.J., V.F. Castellucci, and E.R. Kandel. 1971. An analysis of dishabituation and sensitization of the gill-withdrawal reflex in Aplysia. Intern. J. Neurosci. 2: 79-98.

Castellucci, V.F. and E.R. Kandel. 1976. Presynaptic facilitation as a mechanism for behavioral sensitization in Aplysia. Science 194: 1176-1178.

Castellucci, V.F., H. Pinsker, I. Kupfermann, and E.R. Kandel. 1970. Neuronal mechanisms of habituation and dishabituation of the gill-withdrawal reflex in Aplysia. Science 167: 1745-1748.

Cropper, E.C., P.E. Lloyd, W. Reed, R. Tenenbaum, I. Kupfermann, and K.R. Weiss. 1987. Multiple neuropeptides in cholinergic motor neurons of Aplysia. Evidence for modulation intrinsic to the motor circuit. Proc. Natl. Acad. Sci. 84: 3486-3490.

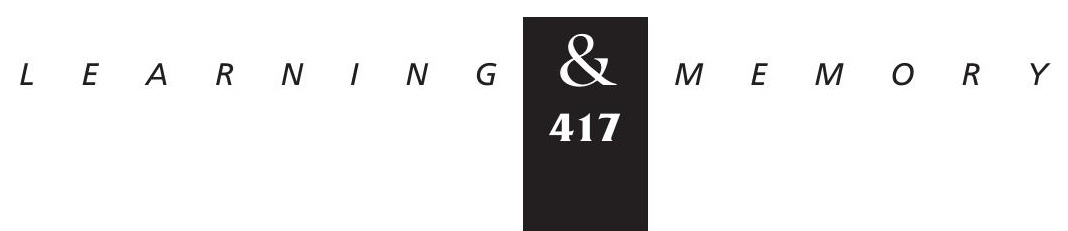




\section{Burrell and Sahley}

Cropper, E.C., M.W. Miller, F.S. Vilim, R. Tenenbaum, I. Kupfermann, and K.R. Weiss. 1990. Buccalin is present in the cholinergic motor neuron B16 Aplysia and it depresses accessory radula closer muscle contractions evoked by stimulation of B16. Brain Res. 512: 175-179.

Davis, M. 1989. Sensitization of the acoustic startle response by footshock. Behav. Neurosci. 103: 495-503.

Davis, M. and S.E. File. 1984. Intrinsic and extrinsic mechanisms of habituation and sensitization: Implications for the design and analysis of experiments. In Habituation, sensitization, and behavior (ed. H.V.S. Peeke and L.F. Petrinovich), pp. 287-323. Academic Press, New York, NY.

Davis, M. and A.R. Wagner. 1969. Habituation of the startle response under an incremental sequence of stimulus intensities. J. Comp. Physiol. Psychol. 67: 486-492.

Ehrlich, J., N. Boulis, T. Karrer, and C.L. Sahley. 1992. Differential effects of serotonin depletion on sensitization and dishabituation. J. Neurobiol. 23: 270-279.

Gardner-Medwin, A.R., J.K. Jansen, and T. Taxt. 1973. The "giant" axon of the leech. Acta Physiol. Scand. 87: 30-31.

Goldberg, J.I. and K. Lukowiak. 1984. Transfer of habituation in Aplysia: Contribution of heterosynpatic pathways in habituation of the gill-withdrawal reflex. J. Neurobiol. 15: 395-411.

Groves, P.M., D. Lee, and R.F. Thompson. 1970. Effects of stimulus frequency and intensity on habituation and sensitization in acute spinal cat. Physiol. Behav. 4: 383-388.

Harris-Warrick, R.M. 1991. Modulation of neural networks for behavior. Ann. Rev. Neurosci. 14: 39-57.

Hawkins, R.D., V.F. Castellucci, and E.R. Kandel. 1981. Interneurons involved in mediation and modulation of gill-withdrawal reflex in Aplysia. II. Identified neurons produce heterosynaptic facilitation contributing to behavioral sensitization. J. Neurophys. 45: 315-328.

Hawkins, R.D., E.R. Kandel, and S.A. Siegelbaum. 1993. Learning to modulate transmitter release: Themes and variations in synaptic plasticity. Ann. Rev. Neurosci. 16: 625-665.

Hinde, R.A. 1970. Behavioral habituation. In Short-term changes in neural activity and behavior (ed. G. Horn and R.A. Hinde), pp. 3-40. Cambridge University Press, London, UK.

Katz, P.S. and W.N. Frost. 1995. Intrinsic neuromodulation in the Tritonia swim CPG: Serotonin mediates both neuromodulation and neurotransmission by the dorsal swim interneurons. J. Neurophys. 74: 2281-2294.

1996. Intrinsic neuromodulation: Altering neuronal circuits from within. Trends Neurosci. 19: 54-61.

Keating, H.H. and C.L. Sahley. 1996. Localization of the myomodulin-like immunoreactivity in the leech CNS. J. Neurobiol. 30: 374-384.

Krasne, F.G.and T.M. Teshiba. 1995. Habituation of an invertebrate escape reflex due to modulation by higher centers rather that local events. Proc. Natl. Acad. Sci. 92: 3362-3366.

Lewis, J.E. and W.B. Kristan. 1998. A neuronal network for computing population vectors in the leech. Nature 391: 76.

Lockery, S.R. and W.B.J. Kristan. 1990a. Distributed processing of sensory information in the leech. I. Input-output relations of the local bending reflex. J. Neurosci. 10: $1811-1815$.

1990b. Distributed processing of sensory information in the leech. II. Identification of interneurons contributing to the local bending reflex. J. Neurosci. 10: 1816-1829.

1991. Two forms of sensitization of the local bending reflex of the medicinal leech. J. Comp. Physiol. A 168: 165-177.

Lockery, S.R., J.N. Rawlins, and J.A. Gray. 1985. Habituation of the shortening reflex in the medicinal leech. Behav. Neurosci. 99: 333-341.

Mackintosh, N.J. 1974. Generalization. In The psychology of animal learning, pp. 485-542. Academic Press, New York, NY.

Magni, F. and M. Pelligrino. 1978. Neural mechanisms underlying the segmental and generalized cord shortening reflexes in the leech. J. Comp. Physiol. A. Sens. Neural Behav. Physiol. 124: 339-351.

Mason, A. and K.J. Muller. 1996. Accurate synapse regeneration despite ablation of the distal axon segment. Eur. J. Neurosci. 8: 11-20.

Meyrand, P., J. Simmers, and M. Moullins. 1991. Construction of a pattern-generating circuit with neurons of different networks. Nature 351: 60-63.

Modney, B.K., C.L. Sahley, and K.J. Muller. 1997. Regeneration of a central synapse restores nonassociative learning. J. Neurosci. 17: 6478-6482.

Muller, K.J., J.G. Nicholls, and G.S. Stent. 1981. Neurobiology of the leech. Cold Spring Harbor Laboratory, Cold Spring Harbor, NY.

Nicholls, J.G. and D.A. Baylor. 1968. Specific modalities and receptive fields of sensory neurons in CNS of the leech. J. Neurophysiol. (Bethesda) 31: 740-756.

Ort, C.A., W.B.J. Kristan, and G.S. Stent. 1974. Neuronal control of swimming in the medicinal leech. II. Identification and connections of motor neurons. J. Comp. Physiol. 94: 121-154.

Razran, G. 1971. Mind in evolution: An east-west synthesis

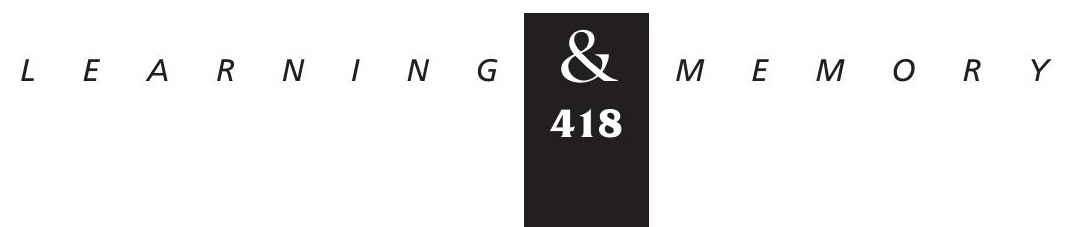


of learned behavior and cognition. Houghton Mifflin Company, Boston, MA.

Sahley, C.L. 1994. Serotonin depletion impairs but does not eliminate classical conditioning in the leech, Hirudo medicinalis. Behav. Neurosci. 108: 1043-1052.

1995. What we have learned from the study of learning in the leech. J. Neurobiol. 27: 434-445.

Sahley, C.L., B.K. Modney, N.M. Boulis, and K.J. Muller. 1994. The $S$ cell: An interneuron essential for sensitization and full dishabituation of leech shortening. J. Neurosci. 14: 6715-6721.

Shaw, B.K. and W.B.J. Kristan. 1995. The whole-body shortening reflex of the medicinal leech: Motor pattern, sensory basis, and interneuronal pathways. J. Comp. Physiol. 177: $667-681$.

Stopfer, M. and T.J. Carew. 1996. Heterosynaptic facilitation of tail sensory neuron synaptic transmission during habituation in tail-induced rail and siphon withdrawal reflexes of Aplysia. J. Neurosci. 16: 4933-4948.

Stopfer, M., X. Chen, Y. Tai, G.S. Huang, and T.J. Carew. 1996. Site specificity of short-term and long-term habituation in the tail-elicited siphon withdrawal reflex of Aplysia. J. Neurosci. 16: 4923-4932.

Stuart, A.E. 1970. Physiological and morphological properties of motoneurones in the central nervous system of the leech. J. Physiol. 209: 627-646.

Thompson, R.F., P.M. Groves, T.J. Teyler, and R.A. Roemer. 1973. A dual-process theory of habituation: Theory and behavior. In Habituation (ed. H.V.S. Peeke and M.J. Herz), pp. 239-271. Academic Press, Orlando, FL.

Weiss, K.R., V. Brezina, E.C. Cropper, S.L. Hooper, M.W. Miller, W.C. Probst, F.S. Vilim, and I. Kupfermann. 1992. Peptidergic co-transmission in Aplysia: Functional implications for rhythmic behavior. Experentia 48: 456-463.

Whim, M.D. and P.E. Lloyd. 1989. Frequency-dependent release of peptide cotransmission from identified motor neurons in Aplysia. Proc. Natl. Acad. Sci. 86: 9034-9038.

Yau, K. 1976. Receptive fields, geometry and conduction block of sensory neurones in the central nervous system of the leech. J. Physiol. 263: 513-538.

Received June 26, 1998; accepted in revised form September 3, 1998 


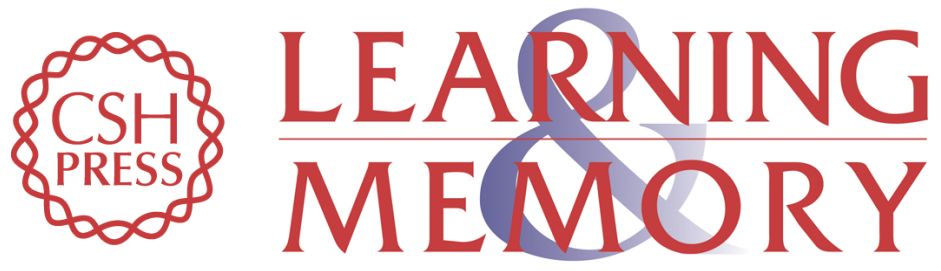

\section{Generalization of Habituation and Intrinsic Sensitization in the Leech}

Brian D. Burrell and Christie L. Sahley

Learn. Mem. 1998, 5:

Access the most recent version at doi:10.1101//m.5.6.405

References This article cites 43 articles, 12 of which can be accessed free at: http://learnmem.cshlp.org/content/5/6/405.full.html\#ref-list-1

License

Email Alerting Receive free email alerts when new articles cite this article - sign up in the box at the Service top right corner of the article or click here. 